https://helda.helsinki.fi

\title{
The comparison of dissolved organic matter in hydrochars and biochars from pig manure
}

\section{Song, Chengfang}

2020-06-10

Song , C , Shan , S, Yang , C, Zhang , C , Zhou , X, Ma , Q, Yrjälä, K, Zheng, H \& Cao , Y 2020 , ' The comparison of dissolved organic matter in hydrochars and biochars from pig manure ' , The Science of the Total Environment , vol. 720,137423 . https://doi.org/10.1016/j.scitotenv.2020.137423

http://hdl.handle.net/10138/326747

https://doi.org/10.1016/j.scitotenv.2020.137423

cc_by_nc_nd

acceptedVersion

Downloaded from Helda, University of Helsinki institutional repository.

This is an electronic reprint of the original article.

This reprint may differ from the original in pagination and typographic detail.

Please cite the original version. 


\section{Journal Pre-proof}

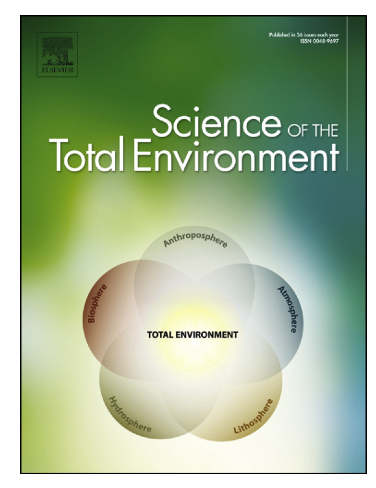

The comparison of dissolved organic matter in hydrochars and biochars from pig manure

Chengfang Song, Shengdao Shan, Chao Yang, Cheng Zhang, Xiaoqing Zhou, Qi Ma, Kim Yrjälä, Huabao Zheng, Yucheng Cao

PII: $\quad$ S0048-9697(20)30933-5

DOI: $\quad$ https://doi.org/10.1016/j.scitotenv.2020.137423

Reference: $\quad$ STOTEN 137423

To appear in: $\quad$ Science of the Total Environment

Received date: $\quad 29$ October 2019

Revised date: $\quad 17$ February 2020

Accepted date: $\quad 17$ February 2020

Please cite this article as: C. Song, S. Shan, C. Yang, et al., The comparison of dissolved organic matter in hydrochars and biochars from pig manure, Science of the Total Environment (2020), https://doi.org/10.1016/j.scitotenv.2020.137423

This is a PDF file of an article that has undergone enhancements after acceptance, such as the addition of a cover page and metadata, and formatting for readability, but it is not yet the definitive version of record. This version will undergo additional copyediting, typesetting and review before it is published in its final form, but we are providing this version to give early visibility of the article. Please note that, during the production process, errors may be discovered which could affect the content, and all legal disclaimers that apply to the journal pertain.

(C) 2020 Published by Elsevier. 
The comparison of dissolved organic matter in hydrochars and biochars from pig manure Chengfang Song ${ }^{\mathrm{a}}$; Shengdao Shan ${ }^{\mathrm{b}}$; Chao Yang ${ }^{\mathrm{c}}$; Cheng Zhang ${ }^{\mathrm{a}}$; Xiaoqing Zhou ${ }^{\mathrm{a}}$; Qi Ma ${ }^{\mathrm{a}}$; Kim Yrjälä ${ }^{\mathrm{a}, \mathrm{d}}$; Huabao Zheng ${ }^{\mathrm{a}^{*}}$; Yucheng $\mathrm{Cao}^{\mathrm{a}^{*}}$

${ }^{a}$ Zhejiang Province Key Laboratory of Soil Contamination Bioremediation, Zhejiang A\&F University, Hangzhou 311300, China

${ }^{\mathrm{b}}$ Zhejiang Province Key Laboratory of Recycling and Ecological Treatment of Waste Biomass, Zhejiang University of Science and Technology, Hangzhou 310023, China

${ }^{c}$ School of Environmental Science and Engineering, Tianjin University, Tianjin 300350, China

${ }^{\mathrm{d}}$ Department of Forest Sciences, University of Helsinki, Helsinki, Finland

Abstract: Dissolved organic matter (DOM) has an important effect on soil fertility, activity of microorganisms and transport of contaminants. In this study, DOM released by the hydrochar and biochar prepared under various conditions from pig manure, was assessed using a combination of UV-Visible spectroscopy, fluorescence excitation-emission (EEM) spectrophotometry and ${ }^{1} \mathrm{H}$-nuclear magnetic resonance $\left({ }^{1} \mathrm{H}-\mathrm{NMR}\right)$.. The dissolved organic carbon (DOC) extracted from the hydrochar and biochar ranged from $3.34-11.96 \%$ and $0.38-0.48 \%$, respectively, and the highest DOM was released by $\mathrm{HCK} 0.5\left(180{ }^{\circ} \mathrm{C}\right.$ and $\left.0.5 \% \mathrm{KOH}\right)$. The aliphatic compounds were most common in DOM which mainly included three humic acid-like and one protein-like substance. The hydrochar-DOM had a larger molecular weight and lower aromaticity than biochar-DOM, but the effect of temperature on the DOM characteristics of hydrochar and biochar was opposite. The acidic treatment increased the content of functional groups containing oxygen and nitrogen in hydrochar-DOM, and alkaline treatment increased the content of aliphatic compounds. The results obtained are beneficial to select carbonation process and guide the rational application of hydrochar and biochar from pig manure in soil remediation field. 
Keywords: Pig manure; Hydrochar; Biochar; Dissolved organic matter; Fluorescence; 'H NMR

\section{Introduction}

Dissolved organic matter (DOM) is often operationally defined as a continuum of organic molecules of different sizes and structures that pass through a filter of $0.45 \mu \mathrm{m}$ pore size, including dissolved organic carbon (DOC), dissolved organic nitrogenous and dissolved organic phosphorus (Kalbitz et al., 2000) compounds. Soil solution contains different amounts of DOM that is made up of a small amount of organic acids, sugars, amino acids and most intricate molecules of high molecular weight, namely, humic substances (Herbert and Bertsch, 1995; Kalbitz et al., 2000). DOM is the most dynamic organic component in soil, which is an important factor affecting soil formation (Dawson et al., 1978), mineral weathering (Raulund-Rasmussen et al., 1998), microbial growth and metabolism (Freeman et al., 2001), organic matter decomposition (Clark et al., 2010) and pollutant transport (Li et al., 2017; Huang et al., 2018). In farmland soil, in addition to plant litter, root exudates and the decomposition of microorganisms' biomass, exogenous organic materials (such as returning straw, various farm fertilizers, etc.) is another important source of DOM (Chantigny, 2003). Once applied in soil, these exogenous organic materials can directly change the content and composition of soil DOC (Beesley et al., 2010; Dittmar et al., 2012).

In recent years, with the in-depth study of the application of biochar in soil remediation, the biochar-derived DOM has attracted considerable attention of researchers for its important role in determining biochar's potential application (Smith et al., 2016; Liu et al., 2019; Huang et al., 2019). Previous studies have shown that DOM of biochar plays an important role in controlling the fate and transport of organic contaminants (Chen et al., 2018; Fu et al., 2018), metals (Borggaard et al., 2019; Huang et al., 2019), microbial activities (Tang et al., 2016; Chen et al., 2018) and plant growth (Korai et al., 2018; Wu et al., 2018). In addition, some findings have confirmed that the content, composition and 
characteristics of biochar DOM are related to the biochar source, its preparation process and extraction and used analysis methods (Jamieson et al., 2014; Li et al., 2017; Liu et al., 2019; Huang et al., 2019). For instance, Tang et al. (2016) showed that DOC from soybean straw biochar had the highest DOC content and relatively higher degree of humification in five different raw biochars. Taherymoosavi et al. (2017) found that the concentrations of DOC appeared to be the highest in biochar at $450{ }^{\circ} \mathrm{C}$. Wu et al. (2018) found that the biochar-derived DOC extracted by alkali was the highest and that extracted with distilled water extract was the lowest.

Knowledge of the molecular properties influencing DOC is useful for optimizing the preparation process and to infer reactivity and mobility of biochar, as well as its reactivity with other chemicals within soil. Various spectroscopic techniques (FTIR, UV-Vis and fluorescence spectroscopy) and nuclear magnetic resonance (13C NMR and 1H NMR) have been used to assess the characteristics of DOM (He et al., 2011). The spectroscopic techniques are effective means to study the structural characteristics of DOM in water, soil and biochar because of its simple operation, high sensitivity no interference with the samples (Korshin et al., 1997; He et al., 2011; Li et al., 2017).. The absorbance values of different wavelengths characterize the different composition characteristics, agglomeration degree and molecular weight of DOM. The value of $\mathrm{A}_{254} \mathrm{~nm} / \mathrm{TOC}\left(\mathrm{SUVA}_{254}\right)$ and $\mathrm{A}_{250 \mathrm{~nm}} / \mathrm{A}_{365} \mathrm{~nm}$ have widely been used as indicators of aromatization degree, molecular weight and composition (Korshin et al., 1996; Tang et al., 2016; Araújo et al., 2019). For example, Wang et al. (2015) compared the main factors affecting the molecular weight (reflected by $\mathrm{A}_{250 \mathrm{~nm}} / \mathrm{A}_{365} \mathrm{~nm}$ ) and aromaticity (reflected by SUVA254) of DOM extracted from different heat treated tree fragments. Wu et al. (2019) have determined the DOM distribution of wetland plant biochar at $300-700{ }^{\circ} \mathrm{C}$ by fluorescence excitation-emission and found them to vary significantly with pyrolysis temperatures. Nuclear magnetic resonance spectroscopy can reveal the source of DOM and the evolution of various fine structures by revealing molecular skeleton structure 
and functional group composition (Lam and Simpson, 2008). Lu et al. (2004) analyzed DOM in ground waters sampled from a dairy/crop production area using $1 \mathrm{H}$ nuclear magnetic resonance and distinguished the source of DOM by different characteristic resonance.

Chinese pig production accounts for $50 \%$ of the world total and 3.8 billion tonnes pig manure are annually produced in China (Song et al., 2018), which are usually treated as organic fertilizer introducing a lot of DOM into soil. Traditional composting of manure has the following disadvantages: Long composting cycle and the occupation of large land areas strongly associated with the season based odor release. In recent years some studies have confirmed that carbonation of livestock and poultry faeces can deodorize, eliminate pathogens, fix carbon and recover nutrients (Dai et al., 2017; Wu et al., 2017; Reza et al., 2018). Compared with pig manure compost, hydrochars have higher recovery rate of nutrients and lower content of heavy metals (Fornes et al., 2015; Song et al., 2019). In addition, hydrochar has the characteristics of higher proportion of unstable organic carbon and faster mineralization rate (Libra et al., 2011). Consequently, the dry and wet carbonation of pig manure could not only treat pig manure quickly and efficiently, but also obtain pig manure hydrochars and biochar with potential soil remediation properties (Liu et al., 2017; Song et al., 2019). To the best of our knowledge here has been no investigation of DOM in pig manure hydrochar and biochars.

The main fractions and structure characteristics of DOM in pig manure hydrochar and biochar remain unclear and the differences of DOM between hydrochar and biochar have not yet been compared. The objective of this study was to: (i) determine DOM concentration in pig manure hydrochar and biochar; (ii) analyse the main component and structural characteristics of DOM by using of EEM-fluorescence spectroscopy, UV-visible absorption and 1H-nuclear magnetic resonance; (iii) compare DOM differences between hydrochar and biochars; (iv) investigate the effects of temperature, acidic and alkaline media on DOM released by hydrochars. The findings could provide novel insights 
into the optimization of hydrothermal carbonation process and strategies for in-situ remediation of contaminated soils and carbon fertilizer applications in crop production.

\section{Materials and methods}

\subsection{Materials}

The pig manure used in this study was collected from three pig farms located in Hangzhou City, Zhejiang Province, China in September 2018. It was transferred to the laboratory and stored for 2 days at room temperature $\left(20^{\circ} \mathrm{C}-25^{\circ} \mathrm{C}\right)$. After being evenly stirred, it was sealed in plastic bags, and then stored in a refrigerator at $-20^{\circ} \mathrm{C}$ until use. The pig manure with $83.1 \%$ moisture was dried at $105^{\circ} \mathrm{C}$ and main nutrient element content was determined. The pig manure had $31.9 \%$ total organic carbon, $19.3 \%$ readily oxidizable carbon, $17.0 \%$ microbial biomass carbon, $8.4 \%$ of dissolved organic carbon (DOC), $2.49 \% \mathrm{TN}$ and $1.2 \% \quad \mathrm{TP}$.

\subsection{Hydrochar production}

The hydrothermal carbonation of the pig manure was carried out in a carbonization furnace. Approximate $300 \mathrm{~g}$ pig manure was placed in a $500 \mathrm{~mL}$ stainless steel reactor with a Teflon tube with

following procedures: (1) The reactor was heated up to certain temperatures $\left(170,180\right.$ or $\left.190{ }^{\circ} \mathrm{C}\right)$ with a heating rate of $5{ }^{\circ} \mathrm{C} / \mathrm{min}$ maintained for $1 \mathrm{~h}$ at the final temperature. The hydrochars were consequently designated as $\mathrm{HC} 170, \mathrm{HC} 180$ and $\mathrm{HC} 190$, respectively, with the number following $\mathrm{HC}$ being the reaction temperature $\left({ }^{\circ} \mathrm{C}\right)$. (2) Strong acid $\mathrm{H}_{2} \mathrm{SO}_{4}$ solutions $\left(0,1\right.$, 2, or $3 \mathrm{~mL} \mathrm{H}_{2} \mathrm{SO}_{4}$ diluted to $10 \mathrm{ml}$ aqueous solution) were added to $100 \mathrm{~g}$ pig manure that was hydrothermally carbonized at $180^{\circ} \mathrm{C}$ for $1 \mathrm{~h}$. The hydrochars were designated as HCS0, HCS1, HCS2 and HCS3, respectively, with the number following $\mathrm{HC}$ being the concentration of $\mathrm{H}_{2} \mathrm{SO}_{4}$ (x ml/100 g manure). (3) Strong alkali $\mathrm{KOH}$ solutions (0, 
$0.5,1$, or $1.5 \mathrm{~g} \mathrm{KOH})$ were added to $100 \mathrm{~g}$ pig manure that was hydrothermally carbonized at $180^{\circ} \mathrm{C}$ for 1 h. The hydrochars were designated as HCK0, HCK0.5, HCK1 and HCK1.5, respectively, with the number following $\mathrm{HC}$ being the concentration of $\mathrm{KOH}$ (x g/100 g manure).

\subsection{Biochar production}

A low-oxygen temperature-control carbonization method was used (Wei et al., 2019), comprising the following steps: the unfrozen pig manure was dried, crushed and poured into a porcelain bowl (50ml) with a tightly fitting lid, and placed in a muffle furnace for pyrolysis for $1 \mathrm{~h}$ at different temperatures $\left(200,300,400\right.$ and $\left.500^{\circ} \mathrm{C}\right)$. The resulting biochar samples were ground to 100 mesh $(0.154 \mathrm{~mm})$ and stored for further analysis. Biochar samples were referred to as BCX00 (BC200, BC300, BC400 and BC500), with X00 representing the final pyrolysis temperature $\left(200,300,400\right.$ and $\left.500{ }^{\circ} \mathrm{C}\right)$.

\subsection{DOC extraction and analysis}

DOM was extracted from the hydrochar and biochar, as previously reported (Song et al., 2015). Briefly, the dried $10 \mathrm{~g}$ samples of the $2 \mathrm{~mm}$ sieve was added to $20 \mathrm{~g}$ distilled water, the turbid liquid was swayed in a bath table at $25^{\circ} \mathrm{C}$ for $30 \mathrm{~min}$ for complete leaching of dissolved organic matter from hydrochar and biochar and filtered with $0.45 \mu \mathrm{m}$ filter membrane. The filtrate was transferred to a digestion tube and $5 \mathrm{ml}$ concentrated sulfuric acid added and the solution was incubated at room temperature? over night. The digestion tube was heated to $200{ }^{\circ} \mathrm{Cf}$ or 1 hour and $1 \mathrm{~mL}$ perchloric acid added to digest the filtrate to milky white. The digestion solution was cooled, filtered and volume set to $50 \mathrm{ml}$, and sodium hydroxide added to adjust $\mathrm{pH}$ to $4-6$.a. The DOC of the aqueous extract were determined by the TOC analyzer (MultiN / C2100TOC / TN) and the DOM concentration of samples was calculated. 


\subsection{UV-Vis spectroscopy absorption}

The hydrochar and biochar samples were added to pure water $(1 \mathrm{~g} / 10 \mathrm{~mL})$ that was vibrated at room temperature for $24 \mathrm{~h}$, and centrifuged with $10000 \mathrm{r} \mathrm{min}^{-1}$ for $10 \mathrm{~min}$. The supernatant fraction was filtered by 0.45 um filter membrane to obtain DOM liquor. The DOM liquor was diluted with pure water and the DOC adjusted to approximately $20 \mathrm{mg} \mathrm{L}^{-1}$, and the pure water was used as the blank control to scan the UV-vis spectrum. UV-Vis spectroscopy was performed with a spectrophotometer (Metash model UV-8000) in the wavelength range of 190-700 nm. Specific ultraviolet absorbance at $250 \mathrm{~nm}, 254$ $\mathrm{nm}$ and $365 \mathrm{~nm}$ was measured. The $\mathrm{SUVA}_{254}$ was calculated as the absorbance divided by the DOC concentration, $\mathrm{A}_{250} / \mathrm{A}_{365}$ ratio was calculated as the ratio of absorbance at 250 and $365 \mathrm{~nm}$.

\subsection{The fluorescence excitation-emission, EEM spectral analysis}

The DOC of all samples was adjusted to $10 \mathrm{mg} \mathrm{L}^{-1}$ before EEM spectral analysis. The EEM was obtained by scanning emission wavelength (Em) from $280 \mathrm{~nm}$ to $550 \mathrm{~nm}$ at $5 \mathrm{~nm}$ intervals and excitation wavelength (Ex) from $200 \mathrm{~nm}$ to $450 \mathrm{~nm}$ with $5 \mathrm{~nm}$ increments. The EEM spectra of the distilled water were obtained and subtracted from the EEM spectra of all DOM. The obtained EEM were used in PARAFAC modeling using the DOMFluor toolbox in MATLAB 14.0 (MathWorks, Natick, MA, USA). The maximum fluorescence intensity (Fmax) was used as the representative values for each fluorescent component ( $\mathrm{Li}$ et al., 2017).

\subsection{H-NMR analysis}

The dried $10 \mathrm{~g}$ samples of the $2 \mathrm{~mm}$ screen was added to $1.5 \mathrm{~mL}$ deuterium water, which was swayed in a bath table at $25^{\circ} \mathrm{C}$ for $60 \mathrm{~min}$ and centrifuged with $10000 \mathrm{r} \mathrm{min}^{-1}$ for $10 \mathrm{~min}$. The supernatant fraction was filtrated by 0.45 um filter membrane to obtain deuterium water extract that was determined 
by the all-digital fourier superconducting nuclear magnetic resonance spectrometer (Bruker AVANCE III 500MHz).

\subsection{Statistical analysis}

All the treatments were conducted in triplicate and the results were presented as means and standard errors. For DOC analyses, the results were blank-corrected and every 15 th sample was analyzed twice. Two-way analysis of variance (ANOVA) using the SPSS v.170 software package (SPSS Inc., Chicago, IL) was used to compare the effects of treatment temperature, sulfuric acid and potassium hydroxide, and a significance level of 0.05 was applied.

\section{Results and discussion}

\subsection{DOC concentrations in hydrochars and biochars}

The yield of hydrochars ranged from 52 to $79 \%$. (Fig 1a). The effect of temperature and acid/alkaline on yield was consistent with previous research results (Song et al., 2019), and it's not going to be discussed in detail here. The yield of biochars at $170-190^{\circ} \mathrm{C}$ was $28-40 \%$ which was much lower than that of hydrochar, showing that hydrothermal carbonization treatment is more favorable for material recovery.

As shown in Fig 1b, the concentration of DOC in hydrochar was $3.3-12.0 \%$ that sharply decreased from $12.0 \%$ to $3.3 \%$ when the temperature raised from $170{ }^{\circ} \mathrm{C}$ to $190{ }^{\circ} \mathrm{C}$ According to the hydrothermal reaction mechanism proposed by Sevilla and Fuertes (2009) (Sevilla and Fuertes 2009), the hydrothermal process begins with the hydrolysis of precursors into monomers and then the dehydration of monomers, and the final product is formed by the induction of polymerization and aromatization. It could be inferred that the hydrothermal reaction of pig manure at $170{ }^{\circ} \mathrm{C}$ was hydrolysis 
of precursor to monomer and showed higher DOC in $\mathrm{HC} 170$, followed by monomer polymerization and aromatization that resulted in a decrease in DOC. The DOC in the biochar-derived produced at $200{ }^{\circ} \mathrm{C}$ amounted to $0.48 \%$ and then slightly decreased to $0.38 \%$ at $500{ }^{\circ} \mathrm{C}$, which was much lower than that in hydrochar-derived DOC, where $\mathrm{HC} 190$ was 6.96 times higher than that in $\mathrm{BC} 200$, indicating that the reaction mechanism of dry and wet carbonation of pig manure was different. It is generally believed that hydrothermal carbonation is relatively weak and a large part of DOM is not completely polymerized or mineralized, which leads to higher DOC in hydrochars.
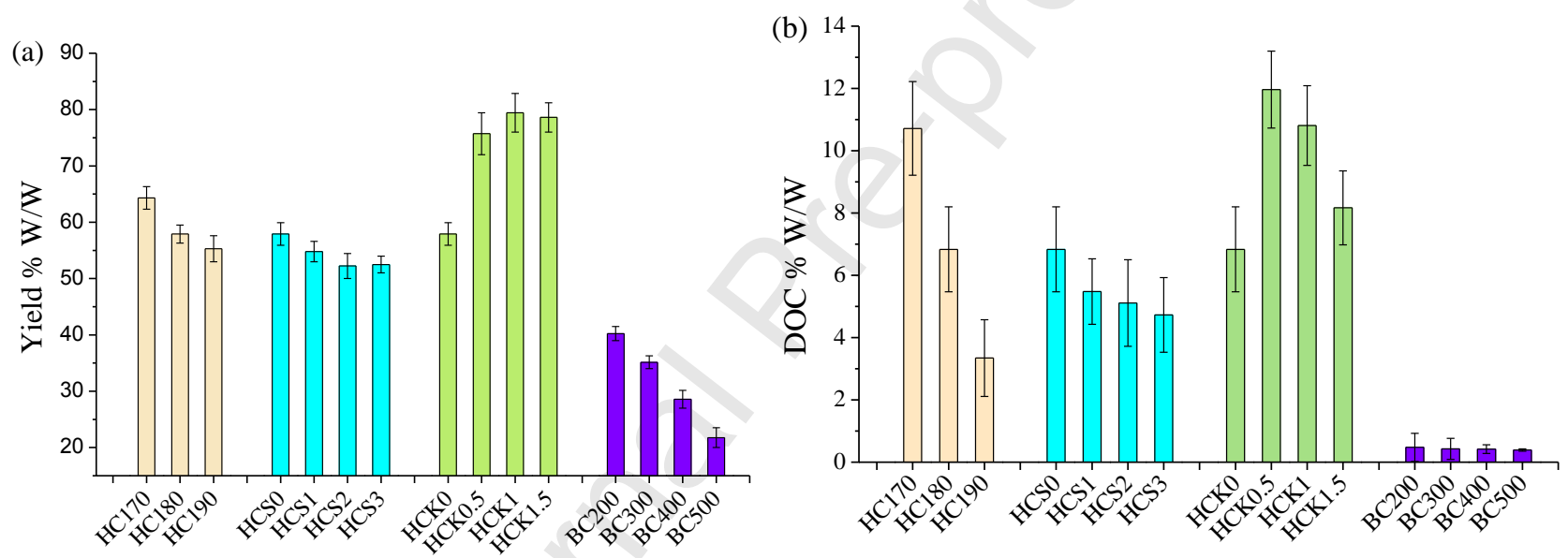

Fig. 1. The yields and concentrations of DOC of hydrochars and biochars.

HC170 - HC190, hydrothermal carbonization at 170 - $190^{\circ} \mathrm{C}$; HCS0 - HCS3, hydrothermal carbonization with sulfuric acid concentration (0 - 3) ml /100 g; HCK0.5 - HCK1.5, hydrothermal carbonization with potassium hydroxide concentration $(0.5-1.5) \mathrm{g} / 100 \mathrm{~g}$; BC200 - BC500, pyrolysis carbonization at $200-500{ }^{\circ} \mathrm{C}$. Data represent averages of at least three experiments with standard errors.

Fig $1 \mathrm{~b}$ shows the effect of the acid/alkaline hydrothermal medium on DOC. The DOC in hydrochar decreased when $\mathrm{H}_{2} \mathrm{SO}_{4}$ was added and more sulfuric acid lead to lower DOC, due to $\mathrm{H}^{+}$catalysis and when DOC was decomposed (Braghirolia et al., 2015). A small amount of alkali $(0.5 \mathrm{~g} / 100 \mathrm{~g})$ could increase hydrolysis reaction which transformed the macromolecule into small molecular weight organic 
compounds increasing the DOC concentration to $11.96 \%$ in $\mathrm{HC} 170$. But when the alkalinity gradually increased, the carbonation reaction was inhibited (Watanabe et al., 2003), and the yield of hydrochar increased it led to the decrease of DOC concentration. Hydrothermal carbonation in dilute alkali environment is thus beneficial to the preparation of hydrochar with high concentration of DOC.

\subsection{Characteristics of EEM-PARAFAC components of hydrochar and biochar}

Four components of hydrochar and biochar were identified by the PARAFAC model (Fig. 2), including three humic-like substances (component 1, 2 and 3), and one protein-like substance (component 4). In detail, the component 1 (C1), identified at Ex/Em of 235/400 and 325/400 nm, fulfills the description of terrestrial humic-like substance (Ishii and Boyer, 2012; Wu et al., 2019). The component 2 (C2) exhibited a peak at 360/425 nm (Ex/Em), was assigned to a fulvic-like substance with the larger molecular size than C1 (Li et al., 2017). The component 3 (C3), detected at Ex/Em of 365/480 nm, was categorized as UVA humic-like substance (Zhang et al., 2019). In addition, C3 was characterized as "reduced quinones" with greater aromaticity than C1 and C2 (Cory and McKnight, 2005). The component 4 (C4), characterized by the peaks at Ex/Em of 280/365 and 280/415 nm, was identified as protein-like component, such as tyrosine and tryptophan, which confirmed the presence of aromatic amino acids-containing proteins in the thermally treated biomass (Erich et al., 2012). 

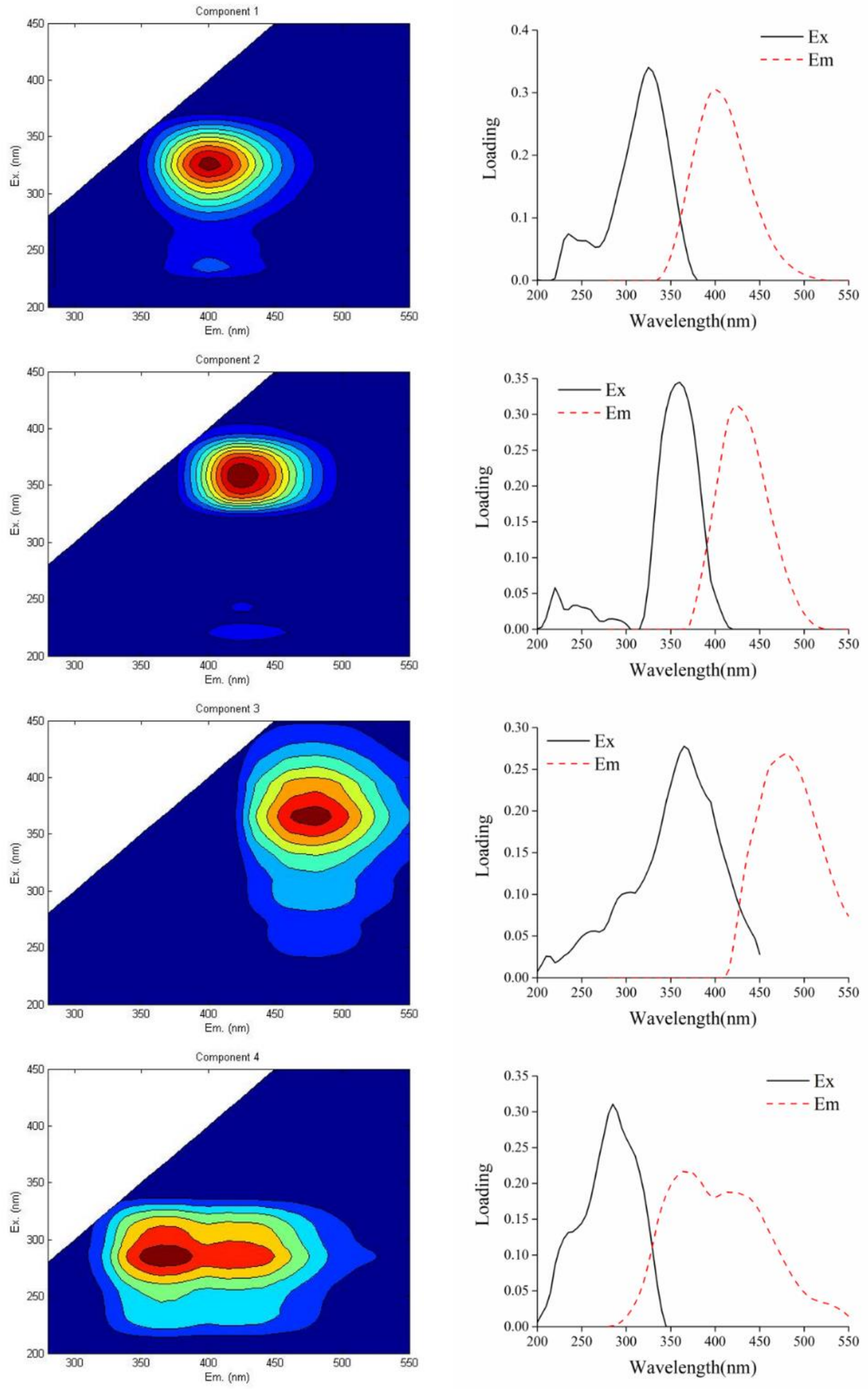
Fig. 2. Four fluorescence components of the DOM obtained from hydrochars and biochars by the EEM-PARAFAC.

To better evaluate the variability of DOM released from the hydrochar and biochar at different temperatures, the relative distribution of four DOM components was determined. As shown in the Fig 3a, the relative quantity of $\mathrm{C} 4$ in three hydrochars ( $\mathrm{HC} 170, \mathrm{HC} 180$ and $\mathrm{HC} 190)$ was $23.1 \%, 21.0 \%$ and $12.0 \%$ respectively, which was higher than that of four biochars (3.7\% - 8.1\%), indicating that the protein-like substance of the hydrochar was more abundant than that of the biochar. C3 was the typical humic-like substance with the high aromaticity. The relative percentage of C3 were all less than $20 \%$ in the hydrochar and the Fmax and relative percentage of $\mathrm{C} 3$ all increased clearly with the temperature. The Fmax was decreasing and the relative percentage remained stable in biochar-derived DOM, which was different from that of hydrochar-derived DOM. Meanwhile, the relative percentage of the aromatic substance $(\mathrm{C} 1, \mathrm{C} 2$ and $\mathrm{C} 3)$ was decreasing with the rising temperature. The result was consistent with $\mathrm{SUVA}_{254}$, indicating that the relative proportion of humic-like components in biochar decreased with the rising temperature. Previous study found that DOM released from biochar prepared at $600{ }^{\circ} \mathrm{C}$ was more aromatic and of larger average molecular weight than that obtained at $350{ }^{\circ} \mathrm{C}$ (Jamieson et al., 2014). In addition, biochar DOM obtained at the low temperature had more carboxyl groups (Zhang et al., 2019). For example, high temperature drives formation of phenolic hydroxyls, by braking the methoxy, and orthooxybenzyl alcohol dehydrated to form methyl quinone (Brebu et al., 2013; Zhang et al., 2019). The results of hydrochar is the opposite, which might be attributed to the differentiation of carbonization method governing the formation of the aromatic component. Hydrochar and biochar produced at low temperatures might play a key role in nutrients release when used as farmland fertilizer. 

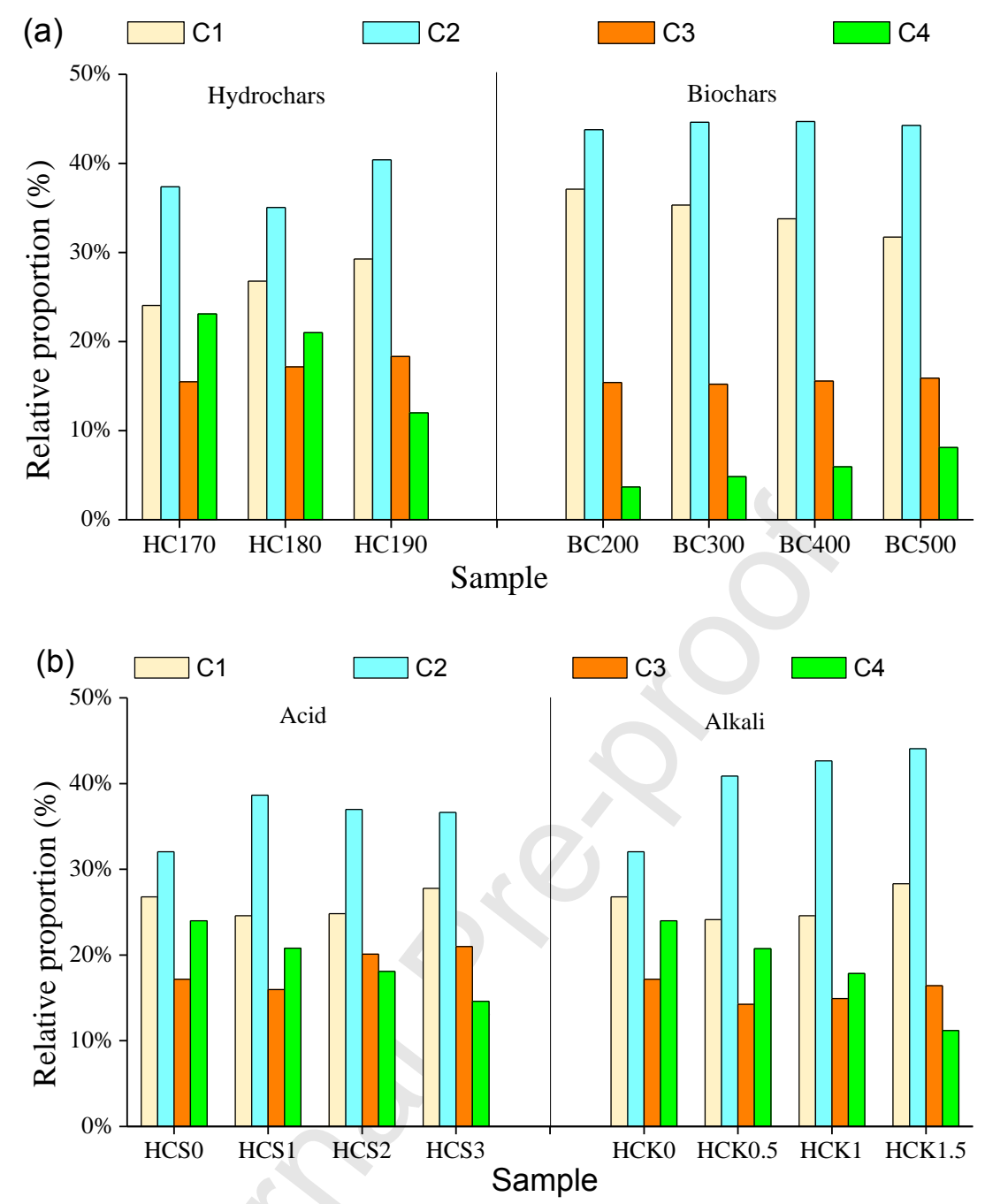

Fig. 3. Relative proportion of EEM-PARAFAC components in DOM, (a) different temperatures of hydrochar and biochar, (b) influence of acid/alkaline of DOM released from hydrochar $\left(180^{\circ} \mathrm{C}\right)$.

The effect of the acid and alkaline of DOM release in hydrochar $\left(180^{\circ} \mathrm{C}\right)$ was shown in the Fig. $3 \mathrm{~b}$. The relative proportion of humic-like substance $(\mathrm{C} 1, \mathrm{C} 2$ and $\mathrm{C} 3)$ increased from $76.0 \%$ to $85.4 \%$ and $88.8 \%$ with the addition of acid/alkaline, indicating that acid/alkaline all could enhance the humic-like substance release from the biochar. Correspondingly, the protein-like substance release was inhibited by the acid/alkaline. The functional group of DOM (e.g. carboxylic, phenolic, alcoholic, carbony) was sensitive to $\mathrm{pH}$ (Yan et al., 2013). The acid/alkaline might weaken the hydrogen bond between the humic-like substance and the hydrochar/biochars, enhancing the release of humic-like substances from 
the hydrochar/biochars.

\section{$3.3 U$ V-vis absorption}

The UV-vis absorption of DOM is related to its unsaturated bond and aromatic structure, and the UV spectral eigenvalues of DOM are commonly used to study its basic properties.

$\mathrm{SUVA}_{254}$ is the average molar absorption rate of DOM at $254 \mathrm{~nm}$, which is the ratio of the absorption coefficient at $254 \mathrm{~nm}$ to the concentration of DOC. The higher $\mathrm{SUVA}_{254}$, the higher is the aromaticity (Yeh et al., 2014). The values of $\mathrm{SUV}_{254}$ for all samples are shown in Fig. 4a. Compared with figure 1, a clear relationship between DOC concentrations and SUVA254 values was found, and the high DOC concentration reflected the low $\mathrm{SUVA}_{254}$ values. The $\mathrm{SUVA}_{254}$ of DOM released from hydrochars and biochars was $0.1-0.34 \mathrm{~L} \mathrm{mg} \mathrm{m}^{-1}$ and $0.42-0.86 \mathrm{~L} \mathrm{mg} \mathrm{m}^{-1}$, respectively, so that the aromaticity of the hydrochar - DOM was lower than that of the biochar. The SUVA 254 of hydrochar extracts significantly increased as the temperature increased $(\mathrm{P}<0.05)$, which could be attributed to polymerization and aromatization of monomers obtained from initial hydrolysis (Braghirolia et al., 2015). For biochars the $\mathrm{SUVA}_{254}$ values sharply decreased with temperature increase in current study, but Wei et al. (2019) found that the SUVA 254 of DOM from the pig manure biochars increased when the pyrolysis temperature increased to $500{ }^{\circ} \mathrm{C}$, and then decreased. The difference may be due to the different preparation time of biochars in these two studies.I In current study, the carbonation residence time was only 1 hour where the biochar-DOM was dominated by unstable aromatic hydrocarbons which evidently degraded rapidly when the temperature increased. Acidic treatment increased the $\mathrm{SUVA}_{254}$ of DOM from hydrochars, suggesting that sulfuric acid can increase the aromatization of DOM for catalysis, and a little alkalinity can decrease the aromaticity of DOM. 

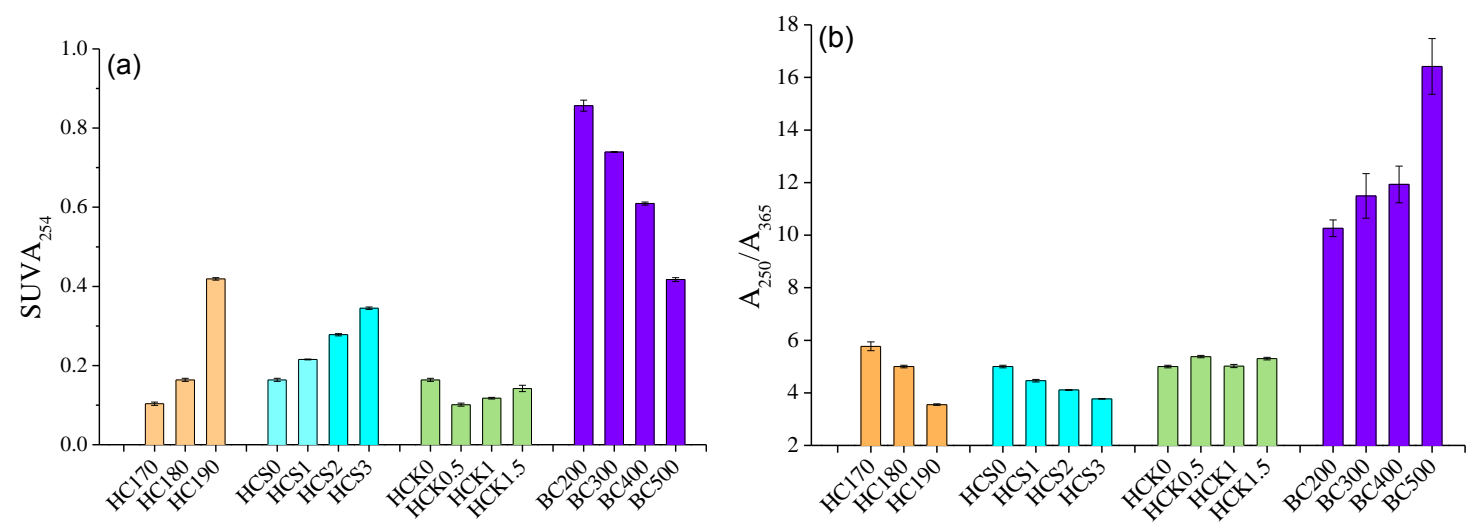

Fig. 4. The $\mathrm{SUVA}_{254}$ (a) and $\mathrm{A}_{250} / \mathrm{A}_{365}$ (b) of DOM released from hydrochars and biochars

In addition, the ratio of light absorbance at $250 \mathrm{~nm}$ to that at $350 \mathrm{~nm}\left(\mathrm{~A}_{250} / \mathrm{A}_{365}\right)$ is widely used as a proxy for DOM molecular weight, i.e., high and low $\mathrm{A}_{250} / \mathrm{A}_{365}$ values represent low and high molecular weight DOM (Fan et al., 2016). In current study, the $\mathrm{A}_{250} / \mathrm{A}_{365}$ ratio of DOM from hydrochars was always lower than that of DOM from biochars (Fig. 4b), which indicated that the hydrochar extracts had a higher molecular weight than those of biochars. With the increase of temperature, the molecular weight of DOM in hydrochars increased, which further supports the idea that polymerization and aromatization of monomers obtained from initial hydrolysis $\left(170^{\circ} \mathrm{C}\right)$ increased with temperature. The molecular weight of DOM in biochars decreased at higher temperatures, in particular from $400{ }^{\circ} \mathrm{C}$ to $500{ }^{\circ} \mathrm{C}$, which also was reported by Lin et al. (2012). The results showed that the macromolecules in biochar-derived DOM were degraded at higher temperature. In this study, it was also found that the trend of $\mathrm{A}_{250} / \mathrm{A}_{365}$ was opposite to SUVA254, which is consistent with previous studies (Guéguen et al., 2012). Acidic treatment increased the molecular weight of DOM from hydrochars but alkalinity had little effect on DOM.

\section{$3.3{ }^{1} H$-NMR of DOM in hydrochars and biochars}

The ${ }^{1} \mathrm{H}-\mathrm{NMR}$ chemical shift is mainly divided into three regions (Wilson et al., 1983): (1) $0.5-3.1$ 
ppm, the signal mainly originates from the aliphatic structure of multi-branch chain and the absorption of $\mathrm{H}$ in the terminal methyl of polymethylene chain; (2) 3.1- $5.5 \mathrm{ppm}$, the signal is the absorption of $\mathrm{H}$ on carbon connected to oxygen (or nitrogen) (mainly carbohydrates, organic amines, methoxyl substances) and aliphatic ring $\mathrm{H}$, and the 4.6 - $4.8 \mathrm{ppm}$ signal is the water peak; (3) $5.5-10.0 \mathrm{ppm}$, the signal is mainly attributed to the contribution of $\mathrm{H}$ in the aromatic structure. In current study, each sample has different degrees of absorption in the three chemical shift regions. The total $\mathrm{H}$ content of the sample after deducting the integral area of the solvent peak is assumed to be $100 \%$. The percentage of the integral area of the $\mathrm{H}$ in each chemical shift region of the total $\mathrm{H}$ content is shown in Table 1.
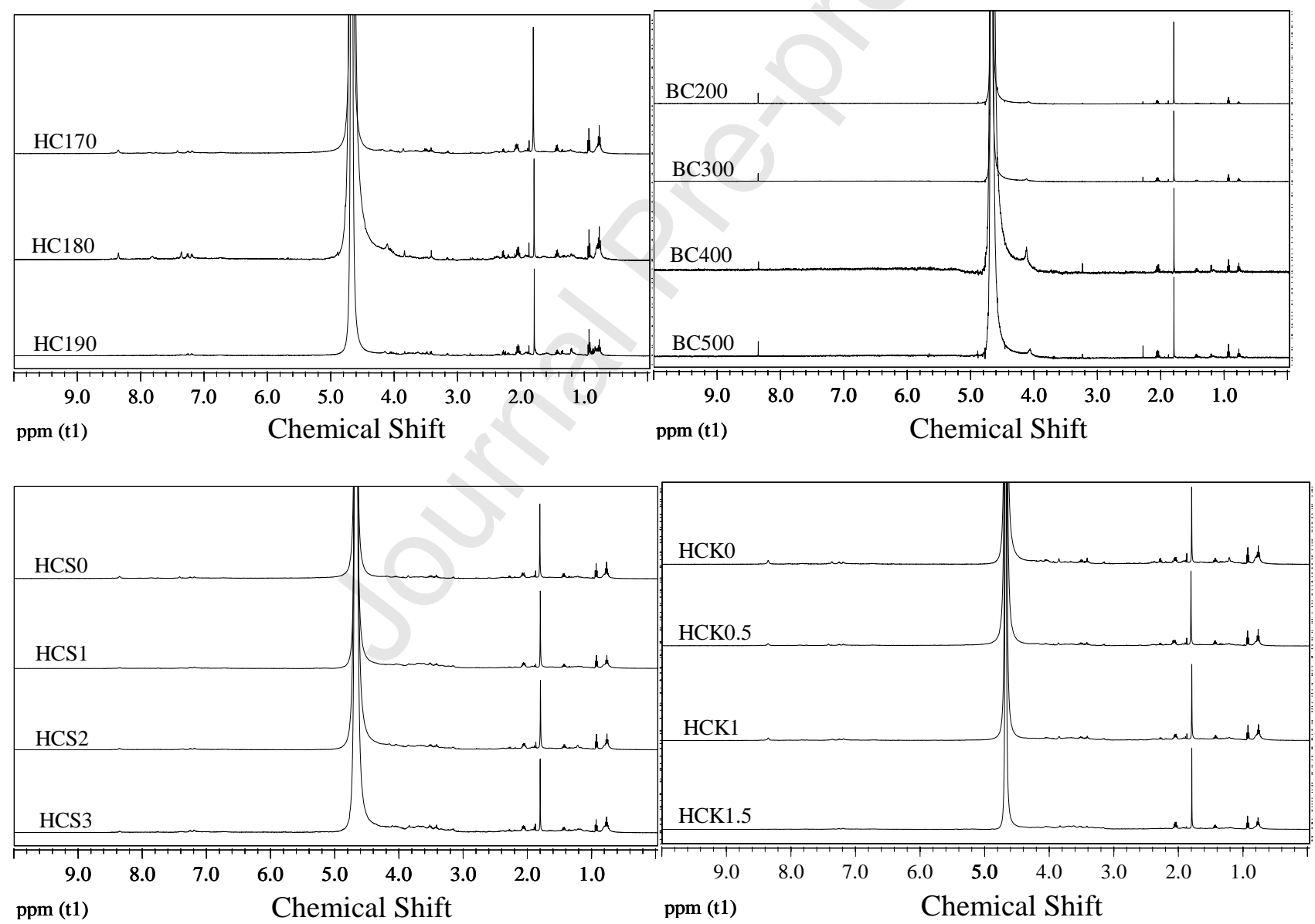

Fig. 5. ${ }^{1} \mathrm{H}-\mathrm{NMR}$ spectrum of DOM released from hydrochars and biochars.

The 1 H-NMR spectra of DOM components in hydrochars and biochars are shown in Fig. 5. 
Common characteristics of the $1 \mathrm{H}-\mathrm{NMR}$ spectra were the strongest peak at $1.8 \mathrm{ppm}$ and more peaks in 0.6 - $2.6 \mathrm{ppm}$, showing a large number of aliphatic compounds?, carbohydrates, nitrogen and oxygen functional groups in DOM components. Many researchers have found that the DOM from cattle manure and pig manure was dominated by long chain aliphatic carbohydrate (Gomez et al., 2010; Wang et al., 2014). There were signal peaks in the chemical shift of $6.5-8.5$ ppm of DOM, showing DOM components also contained aromatic substances. Compared with hydrochars, biochars had fewer peaks and the shape was sharp, which indicated fewer types of compounds in DOM from biochars. The catalytic hydrothermal carbonization of the acid and the base did not obviously change the peak characteristics of 1H-NMR spectra of the DOM.

\section{Table 1}

Relative proportion of 1H-NMR components of DOM released from hydrochars and biochars.

\begin{tabular}{cccc}
\hline $\begin{array}{c}\text { chemical } \\
\text { shift }\end{array}$ & $\begin{array}{c}0.5-3.1 \\
\text { ppm }\end{array}$ & $\begin{array}{c}3.1-5.5 \\
\text { ppm }\end{array}$ & $\begin{array}{c}5.5-10 \\
\text { ppm }\end{array}$ \\
\hline HC170 & 60.69 & 29.03 & 10.28 \\
HC180 & 58.58 & 26.68 & 14.75 \\
HC190 & 50.37 & 31.58 & 18.05 \\
\hline BC200 & 41.96 & 31.28 & 26.77 \\
BC300 & 43.54 & 33.29 & 23.17 \\
BC400 & 45.02 & 35.60 & 19.39 \\
BC500 & 49.08 & 35.07 & 15.85 \\
\hline HCS1 & 45.82 & 46.71 & 7.47 \\
HCS2 & 42.99 & 47.69 & 9.32 \\
HCS3 & 46.86 & 42.03 & 11.11 \\
\hline HCK0.5 & 66.95 & 19.50 & 13.56 \\
HCK1 & 59.73 & 32.14 & 8.13 \\
HCK1.5 & 60.36 & 26.36 & 13.27 \\
\hline
\end{tabular}

$0.5-3.1 \mathrm{ppm}$, the $\mathrm{H}$ of the aliphatic structure; 3.1- $5.5 \mathrm{ppm}$, the $\mathrm{H}$ of oxygen or nitrogen functional group; 5.5 10. $0 \mathrm{ppm}$, the $\mathrm{H}$ of aromatic structure.

The relative content of $\mathrm{H}$ bound to aliphatic groups with chemical shift of 0.5-3.1 ppm range was the highest, and the relative content of $\mathrm{H}$ bound to aromatic with chemical shift of $5.5-10 \mathrm{ppm}$ was the lowest for both hydrochars and biochars (Table 1). These results showed that the hydrochar and biochar 
DOM from pig manure was mainly aliphatic. For hydrochars the relative content of aliphatic $\mathrm{H}$ decreased and the aromatic $\mathrm{H}$ content increased with increased temperature from $170{ }^{\circ} \mathrm{C}$ to $190{ }^{\circ} \mathrm{C}$, The aliphatic structure of branch chain and the structure of polymethylene chain were thus gradually transformed into aromatic substances with the progress of hydrothermal carbonation, due to polymerization and aromatization of monomers obtained from initial hydrolysis (Braghirolia et al., 2015). It is consistent with the conclusion of ultraviolet absorption spectrum analysis in section 3.3. In acidic conditions, hydrothermal carbonization of pig manure can produce a large amount of organic compounds containing oxygen and nitrogen functional groups. Most oxygen-containing functional groups are acidic and more stable under acidic conditions. Under alkaline condition, the relative content of aliphatic $\mathrm{H}$ in DOM released by hydrochars increased, and a large number of small molecular aliphatic substances were produced by hydrothermal hydrolysis of organic matter catalyzed by alkali (Goswami et al., 2015). The relative content of aromatic substances in DOM from biochars was higher than that of hydrochars but decreased with the increase of temperature, which is consistent with the results of UV and fluorescence spectra.

\section{Conclusion}

The pig manure proved to be an appropriate substrate for thermal conversion to soil restoration agent. More and more attention has been paid to the application of hydrochar and biochar from pig manure in soil remediation, but the feasibility of its use is directly dependent on the various physical and chemical properties including the characteristics of DOM. The study compared the characteristics of DOM in hydrochar and biochar from pig manure, showing that the hydrochar-DOM had better performance than biochar-DOM for higher content, lower aromaticity and more different kinds of organic functional groups Temperature and acidity/alkalinity had clear effects on the characteristics of DOM components in 
hydrochars. Hydrothermal carbonation of pig manure catalyzed by dilute alkali can promote the DOM content and reduce? unstable components in hydrochar. Overall our study extend our understanding of the DOMs in thermal conversion products of pig manure, and it is anticipated to benefit the future development of efficient soil remediation using pig manure.

\section{Acknowledgements}

This study was funded by the National Natural Science Foundation of China (41501341), Zhejiang Province Key Research and Development Plan (2020C01017), Zhejiang Province Natural Science Foundation (LY16D010011), and the 111 Project (D18008). The authors are grateful to the anonymous reviewers for their suggestive comments on the manuscript.

\section{References}

Araújo, E., Strawn, D.G., Morra, M., Moore, A., Ferracciú Alleoni, L.R., 2019. Association between extracted copper and dissolved organic matter in dairy-manure amended soils. Environmental Pollution 246, 1020-1026.

Beesley, L., Moreno-Jiménez, E., Gomez-Eyles, J.L., 2010. Effects of biochar and greenwaste compost amendments on mobility, bioavailability and toxicity of inorganic and organic contaminants in a multi-element polluted soil. Environmental Pollution 158, 2282-2287.

Borggaard, O.K., Holm, P.E., Strobel, B.W., 2019. Potential of dissolved organic matter (DOM) to extract As, Cd, Co, $\mathrm{Cr}, \mathrm{Cu}, \mathrm{Ni}, \mathrm{Pb}$ and $\mathrm{Zn}$ from polluted soils: A review. Geoderma 343, 235-246.

Brebu, M., Tamminen, T., Spiridon, I., 2013. Thermal degradation of various lignins by TG-MS/FTIR and Py-GC-MS. Journal of Analytical and Applied Pyrolysis 104, 531-539.

Braghiroli, F.L., Fierro, V., Parmentier, J., Vidal, L., Gadonneix, P., Celzard, A., 2015. Hydrothermal carbons produced from tannin by modification of the reaction medium: Addition of $\mathrm{H}^{+}$and $\mathrm{Ag}^{+}$. Industrial Crops and Products 77 , 364-374.

Chantigny, M.H., 2003. Dissolved and water-extractable organic matter in soils: a review on the influence of land use and management practices. Geoderma 113, 357-380. 
Chapman, P.J., Edwards, A.C., Cresser, M.S., 2001. The nitrogen composition of streams in upland Scotland: some regional and seasonal differences. Science of The Total Environment 265, 65-83.

Chen, X., Liu, M., Kuzyakov, Y., Li, W., Liu, J., Jiang, C., Wu, M., Li, Z., 2018. Incorporation of rice straw carbon into dissolved organic matter and microbial biomass along a 100-year paddy soil chronosequence. Applied Soil Ecology 130, 84-90.

Clark, J., Ashley, D., Wagner, P., Chapman, P., Lane, S., Evans, C., Heathwaite, A., 2009. Increased temperature sensitivity of net DOC production from ombrotrophic peat due to water table draw-down. Global Change Biology $15,794-807$.

Cory, R.M., McKnight, D.M., 2005. Fluorescence Spectroscopy Reveals Ubiquitous Presence of Oxidized and Reduced Quinones in Dissolved Organic Matter. Environmental Science and Technology 39, 8142-8149.

Dai, L., Yang, B., Li, H., Tan, F., Zhu, N., Zhu, Q., He, M., Ran, Y., Hu, G., 2017. A synergistic combination of nutrient reclamation from manure and resultant hydrochar upgradation by acid-supported hydrothermal carbonization. Bioresource Technology 243, 860-866.

Dawson, H.J., Ugolini, F.C., Hrutfiord, B.F., Zachara, J., 1978. Role of soluble organics in the soil processes of a podzol, central cascades, Washington. 126, 290-296.

Dittmar, T., de Rezende, C.E., Manecki, M., Niggemann, J., Coelho Ovalle, A.R., Stubbins, A., Bernardes, M.C., 2012. Continuous flux of dissolved black carbon from a vanished tropical forest biome. Nature Geoscience 5, 618-622.

Fan, X., Song, J., Peng, P.a., 2016. Temporal variations of the abundance and optical properties of water soluble Humic-Like Substances (HULIS) in PM2.5 at Guangzhou, China. Atmospheric Research 172-173, 8-15.

Fornes, F., Belda, R.M., Lidón, A., 2015. Analysis of two biochars and one hydrochar from different feedstock: focus set on environmental, nutritional and horticultural considerations. Journal of Cleaner Production 86, 40-48.

Freeman, C., Ostle, N., Kang, H., 2001. An enzymic 'latch' on a global carbon store. Nature 409, 149-149.

Fu, H., Wei, C., Qu, X., Li, H., Zhu, D., 2018. Strong binding of apolar hydrophobic organic contaminants by dissolved black carbon released from biochar: A mechanism of pseudomicelle partition and environmental implications. Environmental Pollution 232, 402-410.

Gómez, X., Blanco, D., Lobato, A., Calleja, A., Martínez-Núñez, F., Martin-Villacorta, J., 2011. Digestion of cattle manure under mesophilic and thermophilic conditions: characterization of organic matter applying thermal analysis 
and 1H NMR. Biodegradation 22, 623-635.

Goswami, M., Meena, S., Navatha, S., Prasanna Rani, K.N., Pandey, A., Sukumaran, R.K., Prasad, R.B.N., Prabhavathi Devi, B.L.A., 2015. Hydrolysis of biomass using a reusable solid carbon acid catalyst and fermentation of the catalytic hydrolysate to ethanol. Bioresource Technology 188, 99-102.

Guéguen, C., Burns, D.C., McDonald, A., Ring, B., 2012. Structural and optical characterization of dissolved organic matter from the lower Athabasca River, Canada. Chemosphere 87, 932-937.

He, X.S., Xi, B.D., Jiang, Y.H., He, L.S., Li, D., Pan, H.W., Bai, S.G., 2013. Structural transformation study of water-extractable organic matter during the industrial composting of cattle manure. Microchemical Journal 106, $160-166$.

He, X., Xi, B., Wei, Z., Guo, X., Li, M., An, D., Liu, H., 2011. Spectroscopic characterization of water extractable organic matter during composting of municipal solid waste. Chemosphere 82, 541-548.

Herbert, B.E., Bertsch, P.M., 1995. Characterization of Dissolved and Colloidal Organic Matter in Soil Solution: A Review, in: McFee, W.W., Kelly, J.M. (Eds.), Carbon Forms and Functions in Forest Soils. Soil Science Society of America, Madison, WI, pp. 63-88.

Huang, M., Li, Z., Luo, N., Yang, R., Wen, J., Huang, B., Zeng, G., 2019. Application potential of biochar in environment: Insight from degradation of biochar-derived DOM and complexation of DOM with heavy metals. Science of The Total Environment 646, 220-228.

Ishii, S.K.L., Boyer, T.H., 2012. Behavior of Reoccurring PARAFAC Components in Fluorescent Dissolved Organic Matter in Natural and Engineered Systems: A Critical Review. Environmental Science and Technology 46, 2006-2017.

Jamieson, T., Sager, E., Guéguen, C., 2014. Characterization of biochar-derived dissolved organic matter using UVvisible absorption and excitation-emission fluorescence spectroscopies. Chemosphere 103, 197-204.

Kalbitz, K., Solinger, S., Park, J.H., Michalzik, B., Matzner, E., 2000. Controls on the Dynamics of Dissolved Organic Matter in Soils: A Review. Soil Science 165, 277-304.

Korai, P.K., Xia, X., Liu, X., Bian, R., Omondi, M.O., Nahayo, A., Pan, G., 2018. Extractable pool of biochar controls on crop productivity rather than greenhouse gas emission from a rice paddy under rice-wheat rotation. Scientific Reports 8,802. 
Korshin, G.V., Li, C.-W., Benjamin, M.M., 1997. Monitoring the properties of natural organic matter through UV spectroscopy: A consistent theory. Water Research 31, 1787-1795.

Lam, B., Simpson, A., 2008. Direct 1H NMR spectroscopy of dissolved organic matter in natural waters. The Analyst $133,263-269$.

Li, M., Zhang, A., Wu, H., Liu, H., Lv, J., 2017. Predicting potential release of dissolved organic matter from biochars derived from agricultural residues using fluorescence and ultraviolet absorbance. Journal of Hazardous Materials $334,86-92$.

Li, G., Khan, S., Ibrahim, M., Sun, T.R., Tang, J.F., Cotner, J. B., Xu, Y.Y., 2018. Biochars induced modification of dissolved organic matter (DOM) in soil and its impact on mobility and bioaccumulation of arsenic and cadmium. Journal of Hazardous Materials 348(20), 100-108.

Libra, J.A., Ro, K.S., Kammann, C., Funke, A., Berge, N.D., Neubauer, Y., Titirici, M.M., Fühner, C., Bens, O., Kern, J., Emmerich, K.H., 2011. Hydrothermal carbonization of biomass residuals: a comparative review of the chemistry, processes and applications of wet and dry pyrolysis. Biofuels 2, 71-106.

Li, G., Khan, S., Ibrahim, M., Sun, T.R., Tang, J.F., Cotner, J.B., Xu, Y.Y., 2018. Biochars induced modification of dissolved organic matter (DOM) in soil and its impact on mobility and bioaccumulation of arsenic and cadmium. Journal of Hazardous Materials 348, 100-108.

Lin, Y., Munroe, P., Joseph, S., Henderson, R., Ziolkowski, A., 2012. Water extractable organic carbon in untreated and chemical treated biochars. Chemosphere 87, 151-157.

Liu, C.H., Chu, W., Li, H., Boyd, S.A., Teppen, B.J., Mao, J., Lehmann, J., Zhang, W., 2019. Quantification and characterization of dissolved organic carbon from biochars. Geoderma 335, 161-169.

Liu, Y., Yao, S., Wang, Y., Lu, H., Brar, S.K., Yang, S., 2017. Bio- and hydrochars from rice straw and pig manure: Inter-comparison. Bioresource Technology 235, 332-337.

Lu, J., Chang, A.C., Wu, L., 2004. Distinguishing sources of groundwater nitrate by ${ }^{1} \mathrm{H}$ NMR of dissolved organic matter. Environmental Pollution 132, 365-374.

Raulund-Rasmussen, K., Borggaard, O., Hansen, H., Olsson, M., 2003. Effect of natural soil solutes on weathering rates of soil minerals. European Journal of Soil Science 49, 397-406.

Sevilla, M., Fuertes, A.B., 2009. The production of carbon materials by hydrothermal carbonization of cellulose. 
Carbon 47, 2281-2289.

Smith, C.R., Hatcher, P.G., Kumar, S., Lee, J.W., 2016. Investigation into the Sources of Biochar Water-Soluble Organic Compounds and Their Potential Toxicity on Aquatic Microorganisms. ACS Sustainable Chemistry and Engineering 4, 2550-2558.

Song, C., Li, M., Xi, B., Wei, Z., Zhao, Y., Jia, X., Qi, H., Zhu, C., 2015. Characterisation of dissolved organic matter extracted from the bio-oxidative phase of co-composting of biogas residues and livestock manure using spectroscopic techniques. International Biodeterioration and Biodegradation 103, 38-50.

Song, C.F., Shan, S.D., Müller, K., Wu, S.C., Niazi N.K., Xu, S., Shen, Y., Rinklebe, J., Liu, D., Wang, H.L., 2018. Characterization of pig manure-derived hydrochars for their potential application as fertilizer. Environmental Science and Pollution Research. 25, 25772-25779.

Song, C.F., Yuan W.Q., Shan, S.D., Ma Q., Zhang H.B., Wang X.D., Niazi N.K., Wang H.L., 2020.Changes of nutrients and potentially toxic elements during hydrothermal carbonization of pig manure. Chemosphere. 243, 125331

Song, C.F., Zhang, H.B., Shang, S.D., Wu, S.C., Wang, H.L., Christie, P., 2019. Low-temperature Hydrothermal Carbonization of Fresh Pig Manure: Effects of Temperature on Characteristics of Hydrochars. Journal of Environmental Engineering. 145(6), 04019029

Taherymoosavi, S., Joseph, S., Pace, B., Munroe, P., 2018. A comparison between the characteristics of single- and mixed-feedstock biochars generated from wheat straw and basalt. Journal of Analytical and Applied Pyrolysis 129, 123-133.

Tang, J., Li, X., Luo, Y., Li, G., Khan, S., 2016. Spectroscopic characterization of dissolved organic matter derived from different biochars and their polycylic aromatic hydrocarbons (PAHs) binding affinity. Chemosphere 152, 399-406.

Toufiq Reza, M., Poulson, S.R., Román, S., Coronella, C.J., 2018. Behavior of Stable Carbon and Stable Nitrogen Isotopes during Hydrothermal Carbonization of biomass. Journal of Analytical and Applied Pyrolysis 131, 85-92.

Wang, J.J., Dahlgren, R.A., Chow, A.T., 2015. Controlled Burning of Forest Detritus Altering Spectroscopic Characteristics and Chlorine Reactivity of Dissolved Organic Matter: Effects of Temperature and Oxygen Availability. Environmental Science and Technology 49, 14019-14027.

Wang, K., Li, X., He, C., Chen, C.L., Bai, J., Ren, N.Q., Wang, J.Y., 2014. Transformation of dissolved organic matters in swine, cow and chicken manures during composting. Bioresource technology 168, 222-228. 
Watanabe, M., Inomata, H., Osada, M., Sato, T., Adschiri, T., Arai, K., 2003. Catalytic effects of NaOH and ZrO2 for partial oxidative gasification of n-hexadecane and lignin in supercritical water. Fuel 82, 545-552.

Wei, S., Zhu, M., Fan, X., Song, J., Peng, P.a., Li, K., Jia, W., Song, H., 2019. Influence of pyrolysis temperature and feedstock on carbon fractions of biochar produced from pyrolysis of rice straw, pine wood, pig manure and sewage sludge. Chemosphere 218, 624-631.

Wilson, M., Collin, P., Tate, K.R., 2006. 1H-nuclear magnetic resonance study of a soil humic acid ( New Zealand pasture). Journal of Soil Science 34, 297-304.

Wu, H., Dong, X., Liu, H., 2018. Evaluating fluorescent dissolved organic matter released from wetland-plant derived biochar: Effects of extracting solutions. Chemosphere 212, 638-644.

Wu, H., Qi, Y., Dong, L., Zhao, X., Liu, H., 2019. Revealing the impact of pyrolysis temperature on dissolved organic matter released from the biochar prepared from Typha orientalis. Chemosphere 228, 264-270.

Wu, K., Gao, Y., Zhu, G., Zhu, J., Yuan, Q., Chen, Y., Cai, M., Feng, L., 2017. Characterization of dairy manure hydrochar and aqueous phase products generated by hydrothermal carbonization at different temperatures. Journal of Analytical and Applied Pyrolysis 127, 335-342.

Yan, M., Fu, Q., Li, D., Gao, G., Wang, D., 2013. Study of the pH influence on the optical properties of dissolved organic matter using fluorescence excitation-emission matrix and parallel factor analysis. Journal of Luminescence 142, 103-109.

Yeh, Y.L., Yeh, K.J., Hsu, L.F., Yu, W.C., Lee, M.H., Chen, T.C., 2014. Use of fluorescence quenching method to measure sorption constants of phenolic xenoestrogens onto humic fractions from sediment. Journal of Hazardous Materials 277, 27-33.

Yuan, H., Lu, T., Huang, H., Zhao, D., Kobayashi, N., Chen, Y., 2015. Influence of pyrolysis temperature on physical and chemical properties of biochar made from sewage sludge. Journal of Analytical and Applied Pyrolysis 112, 284-289.

Zhang, B., Zhou, S., Zhou, L., Wen, J., Yuan, Y., 2019. Pyrolysis temperature-dependent electron transfer capacities of dissolved organic matters derived from wheat straw biochar. Science of the Total Environ 696, 133895. 


\section{Journal Pre-proof}

Conflict of Interest The authors have no conflicts of interest to declare. 
Graphical abstract

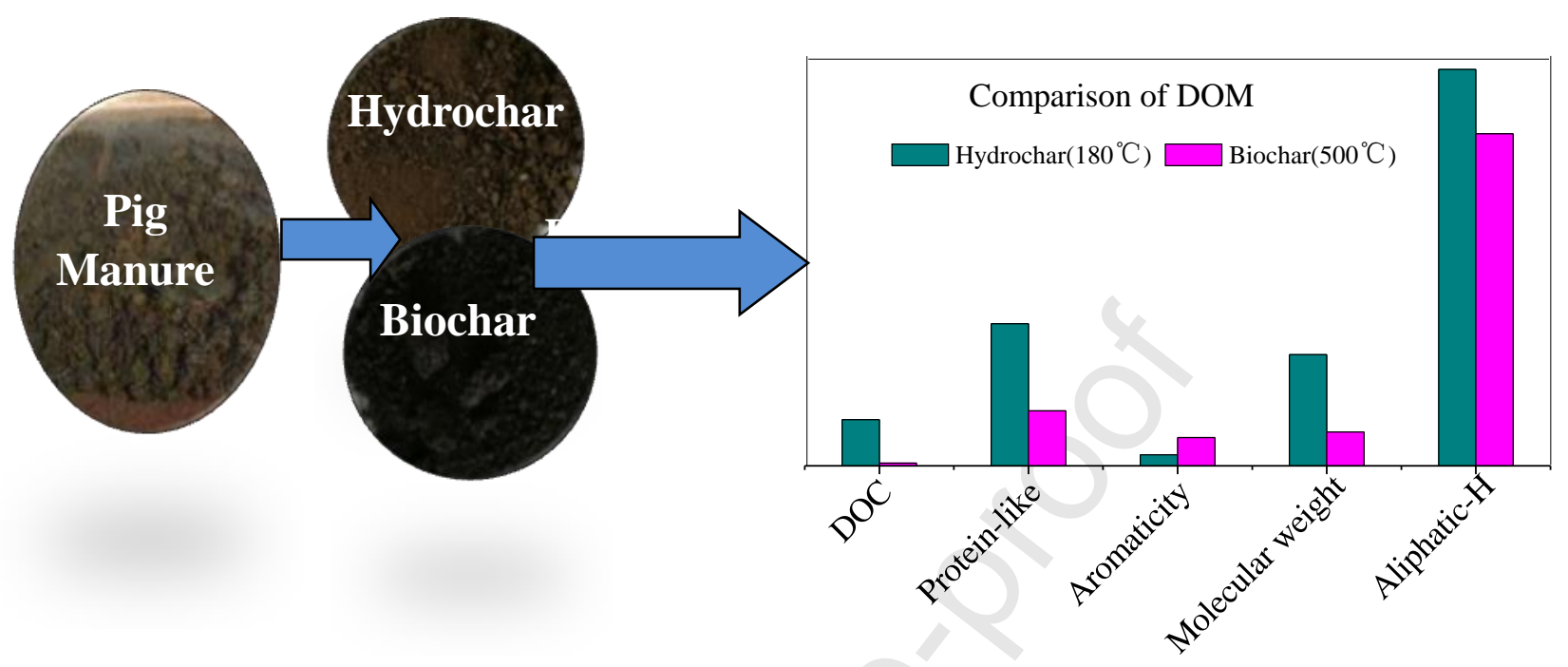




\section{Highlights}

- The higher concentration of DOM in hydrochar than biochar.

- The hydrochar-DOM had a larger molecular weight and lower aromaticity.

- There are mainly three humic acid-like and one protein-like substance in DOM.

- The relative proportion of aliphatic compounds in DOM was the highest.

- The dilute alkali treatment increased the concent and instability of hydrochar-DOM. 